THE INTERNATIONAL

REVIEW OF RESEARCH IN

OPEN AND DISTANCE LEARNING

\title{
Editorial: Volume 12, Number 6
}

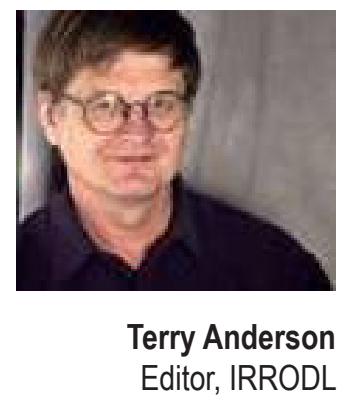

Welcome IRRODL readers (at least those in the northern hemisphere) to another academic year. This issue marks a number of new initiatives for IRRODL as well as a full issue with 10 research articles and four book reviews.

Managing editor Brigette McConkey has been busy improving the look and feel of the journal with more colour, pictures, and hopefully ease of access. You will note the special issue features that are permanently represented by an icon at the bottom of the home page. This attention to the special issue is a means to keep these topical issues alive, and indeed we have added two new articles to the Prior, Experiential, and Informal Learning in the Age of Information and Communication Technologies issue.

We are coming to realize that, unlike in paper journals, a special topic issue in an online journal can remain alive as new content is developed. These new articles can be hyperlinked to the special issue in a regular issue or more tightly focused and aggregated for inclusion within the special issue. You can read these articles or check out the summary included in the special issue editorial.

There is growing interest in "big data" throughout the education, publishing, and general business domains. I have editorialized and we have published a number of articles on journal citation bibliometrics. But in applied fields, readership by practitioners is arguably more important than citation by a small group of researchers. Therefore it would be nice (and either flattering or deflating to authors) to know and to be able to display how many times each article has been downloaded. However, this is not an easy task.

IRRODL is indexed by many sources, and some (notably EPSCO, JALN, ERIC, and SSCI) harvest and distribute the full text of our articles. Therefore, the number downloaded from IRRODL is an unknown fraction of the total number of downloads. Our downloads (in any of our four current formats), therefore, provide only a relative measure of the number of readers and an even more approximate indication of the article's impact on readers. In addition, the download numbers are skewed in that an article published 11 years ago has had 
a much greater length of time to garner downloads than one published this year. Nonetheless, our faithful Open Journal System (OJS) has tracked downloads since we began using this system six years ago. We compiled the following data last summer and found that the "top twenty" articles based on our downloads are as follows:

Article Title

Conceptual Integration in Online Interdisciplinary Study: Current Perspective, Theo- 74807 ries, and Implications for Future Research

An Assessment of the Effectiveness of e-learning in Corporate Training Programs

Plagiarism by Adult Learners Online: A Case Study in Detection and Remediation 31693

Building Sense of Community at a Distance

Blended Learning and Sense of Community: A Comparative Analysis with Traditional 26981 and Fully Online Graduate Courses

Instant Messaging for Creating Interactive and Collaborative m-Learning Environments 26481 Setting the New Standard with Mobile Computing in Online Learning 25987

Theoretical Challenges for Distance Education in the 21st Century: A Shift from Struc- 25484 tural to Transactional Issues

Replacing Face-to-Face Tutorials by Synchronous Online Technologies: Challenges and 23615 Pedagogical Implications

A Comparative Study of Dropout Rates and Causes for Two Different Distance Education 21455 Courses

Learners' Perspectives on what is Missing from Online Learning: Interpretations 19471 through the Community of Inquiry Framework

The Emergence of Open-Source Software in China

19141

Getting the Mix Right Again: An Updated and Theoretical Rationale for Interaction 18670

Learning Objects: Resources For Distance Education Worldwide 18032

Attitudes and Perceptions of Students to Open and Distance Learning in Nigeria 17648

Defining, Discussing and Evaluating Mobile Learning: The Moving Finger Writes and 17008 Having Writ ....

Second Language Acquisition Theories as a Framework for Creating Distance Learning 16903 Courses

Mobile Usability in Educational Contexts: What Have we Learnt?

Integrating Mobile Learning into Nomadic Education Programme in Nigeria: Issues and 16014 Perspectives 
We hope this data is of interest to those new to the field seeking to find the most relevant topics and issues. You can retrieve the full text of all articles published over the last 11 years in our archives. Article authors can also login to OJS (as authors) and see the current number of downloads in all formats by checking out their individual archive.

\section{This Issue}

As always, our regular issues present a variety of articles on diverse issues relevant to both our research and our practitioner communities. In addition, our Book Notes editor, Dr. Peter Cookson, has solicited reviews of four new books, which will be very useful in your decision to order-or prompt your library to do so!

The first article, "The Importance of Interaction for Academic Success in Online Courses with Hearing, Deaf, and Hard-Of-Hearing Students" by Gary Long, Carol Marchetti, and Richard Fasse, provides data on arguably the most contentious issue in distance education pedagogy, the role and effect of interaction. The paper focuses on a compelling context, online learning for the hard-of-hearing, a special needs group that has long benefited from the flexibility of distance education.

I have a special interest in the second article, "Examining Motivation in Online Distance Learning Environments: Complex, Multifaceted, and Situation-Dependent" by Maggie Hartnett, Alison St. George, and Jon Dron, as I served as the external reviewer on the dissertation upon which this work is based. I was impressed by the way motivation theory was applied to a qualitative study, and I think you will be as well.

From New Zealand, we move to Qatar, where Ramzi Nasser, Maha Cherif, and Michael Romanowski detail "Factors that Impact Student Usage of the Learning Management System in Qatari Schools.” Technology adoption and use becomes increasingly important in all countries as the pervasiveness of technology (in myriad instantiations) comes to permeate nearly all forms of education provision.

Regardless of the geography, quality assurance issues in distance education continue to interest and challenge students, parents, faculty, and governments. In "Quality Assurance in Asian Distance Education: Diverse Approaches and Common Culture," authors Insung Jung, Tat Meng Wong, Chen Li, Sanjaa Baigaltugs, and Tian Belawati overview the issue and responses from an Asian perspective.

From Nigeria, Christine I. Ofulue writes "Literacy at a Distance in Multilingual Contexts: Issues and Challenges." Adequate levels of literacy (even in its many definitions) challenge us as distance educators. This article notes the explosive use of mobile computing but reminds us that effective use of a technology for education may be quite a different task than merely trumpeting that technology's use for verbal communication.

The next article again challenges the objectivity of the anonymous peer review process that is staunchly maintained at IRRODL in that I am the co-author. Rest assured that the article was blindly reviewed, and I express my thanks to Dr. Jon Baggaley for stepping in to handle 
the editorial management of the review process. In this article, "Distance Students' Readiness for Social Media and Collaboration," my colleague Bruno Poellhuber and I examine the interest in social media within a large sample of students from four universities in Canada.

The now-familiar community of inquiry model is used in the next article to examine what has become an important new growth area in distance education, the provision of professional doctoral degrees. In "Applying the Community of Inquiry Framework to an Online Professional Practice Doctoral Program,” Swapna Kumar, Kara Dawson, Erik W. Black, Catherine Cavanaugh, and Christopher D. Sessums demonstrate the importance of each of the social, teaching, and cognitive presences. It is interesting to observe the evolution of this model from a tool for assessing online learning to one for designing and then evaluating new programming initiatives.

The next article addresses a critical need in all societies, but situates it in a Canadian context. Effective continuing education opportunities for teachers will be required in these times of rapid change. Thus, "Applying Constructionist Principles to Online Teacher Professional Development” by Nathaniel Mark Ostashewski, Doug Reid, and Susan Moisey presents a model for engaging teachers in online activities while allowing them to remain immersed in their authentic contexts.

The next article documents both the research and work still needed to bridge the digital divide in Africa and other countries. Olugbade Oladokun and Lenrie Aina examine "ODL and the Impact of Digital Divide on Information Access in Botswana.” They provide strategies and suggestions for distance educators struggling to both adjust to and reduce the inequality of access to many of the technology-rich models of distance education.

The research articles in this issue conclude with one of our rare articles published from France. In "Increased Technology Provision and Learning: Giving More for Nothing?” Emmanuelle Quillerou examines the resources that students actually put to effective use in distance education from a suite of tools and resources. Access to online resources makes it very easy to add more and more resources to our learning packages, but, as Quillerou argues, we need to consider their effective use rather than their availability alone.

\section{Book Reviews}

This editorial is likely stretching beyond the attention level of many readers, so I conclude by listing the titles and reviewers of four recent and compelling publications:

- The Perfect Online Course: Best Practices for Designing and Teaching, reviewed by Marta Ruiz-Corbella;

- Web 2.o-Based E-Learning: Applying Social Informatics for Tertiary Teaching, reviewed by Juan Leon;

- Learning with Digital Games: A Practical Guide to Engaging Students in Higher Education, reviewed by Maja Pivec; and 
- Bridging the Knowledge Divide: Educational Technology for Development, reviewed by Aminudin Zuhairi

As always, I extend my sincere thanks to IRRODL authors, reviewers, editors, and our faithful readers! This issue contains works from Indonesia, Austria, Botswana, New Zealand, Spain, United States, Qatar, France, Canada, and Nigeria, among others, demonstrating the global impact of distance education and IRRODL.

\section{Athabasca University $\mathbf{A}$}

(c) 